\title{
Comment on "Systematic Investigation of the Sorption Properties of Polyurethane Foams for Organic Vapors"
}

\author{
Laura Sprunger, ${ }^{\dagger}$ William E. Acree, Jr., ${ }^{*, \dagger}$ and Michael H. Abraham ${ }^{\ddagger}$ \\ Department of Chemistry, University of North Texas, P.O. Box 305070, Denton, Texas 76203-5070, and \\ Department of Chemistry, University College London, 20 Gordon Street, London, WC1H OAJ, U.K.
}

A method was devised for combining experimental partition coefficients measured at different temperatures into a single regression correlation. The proposed method described the 265 experimental air-to-polyurethane ether adsorption coefficients reported by Kamprad and Goss (Kamprad, I.; Goss, K.-U. Anal. Chem. 2007, 79, 42224227 ) to within a standard deviation of $0.084 \mathrm{log}$ units, which is comparable in descriptive ability to the four temperature-specific correlations determined from a regression analysis of the experimental data at each of the temperatures studied.

In a recent paper appearing in this journal, Kamprad and Goss ${ }^{1}$ correlated the sorption properties of polyurethane foams for organic vapors using a modified form of the Abraham linear free energy relationships. For each temperature, relative humidity, and type of foam studied, the authors tabulated the calculated coefficients for their derived correlation equations for absorption coefficients, $K_{\mathrm{PUF}}$,

$$
\begin{array}{r}
\log K_{\mathrm{PUF}}=c_{\mathrm{PUF}}+s_{\mathrm{PUF}} \cdot \mathbf{S}+a_{\mathrm{PUF}} \cdot \mathbf{A}+b_{\mathrm{PUF}} \cdot \mathbf{B}+ \\
v_{\mathrm{PUF}} \cdot \mathbf{V}+l_{\mathrm{PUF}} \cdot \mathbf{L}
\end{array}
$$

where $\mathbf{S}$ refers to the dipolarity/polarizability descriptor of the solute, $\mathbf{A}$ and $\mathbf{B}$ are the measures of the solute's hydrogen-bond acidity and basicity, respectively, $\mathbf{V}$ denotes the soltues' McGowan volume, and $\mathbf{L}$ is the logarithm of the solute's gas-phase dimensionless Ostwald partition coefficient into hexadecane at $298 \mathrm{~K}$. The derived correlations for the different polyurethane ether foam had squared correlation coefficients of $R^{2}>0.97$ and standard errors of less than $0.1 \log$ unit.

The purpose of this comment is to suggest a computational methodology for including experimental data measured at different temperatures into a single Abraham model (or modified Abraham model) correlation. If successful, the new methodology will allow one to derive correlations for many more systems than is currently

\footnotetext{
* To whom correspondence should be addressed. E-mail: acree@unt.edu.

$\dagger$ University of North Texas.

¥ University College London.

(1) Kamprad, I.; Goss, K.-U. Anal. Chem. 2007, 79, 4222-4227.

(2) Abraham, M. H. Chem. Soc. Rev. 1993, 22, 73-83.

(3) Abraham, M. H.; Ibrahim, A.; Zissimos, A. M. J. Chromatogr., A 2004, 1037, 29-47.

(4) Abraham, M. H.; Whiting, G. S.; Carr, P. W.; Ouyang, H. J. Chem. Soc., Perkin Trans. 1998, 2, 1385-1390.
}

possible. Past studies have shown that the basic Abraham model can describe both Gibbs energies ${ }^{2-7}$

$$
\begin{array}{r}
\Delta G_{\mathrm{Solv}}=-2.303 R T \log K=c_{\mathrm{g}}+e_{\mathrm{g}} \cdot \mathbf{E}+s_{\mathrm{g}} \cdot \mathbf{S}+ \\
a_{\mathrm{g}} \cdot \mathbf{A}+b_{\mathrm{g}} \cdot \mathbf{B}+l_{\mathrm{g}} \cdot \mathbf{L}
\end{array}
$$

and enthalpies of solute transfer from the gas phase to a condensed phase ${ }^{8-11}$

$$
\Delta H_{\mathrm{Solv}}=c_{\mathrm{h}}+e_{\mathrm{h}} \cdot \mathbf{E}+s_{\mathrm{h}} \cdot \mathbf{S}+a_{\mathrm{h}} \cdot \mathbf{A}+b_{\mathrm{h}} \cdot \mathbf{B}+l_{\mathrm{h}} \cdot \mathbf{L}
$$

using a common set of five solute descriptors. Equations 2 and 3 employ the Abraham excess molar refraction solute descriptor, E, rather than the McGowan molecular volume. The subscripts "g" and "h" have been added to the equation coefficients to indicate the numerical values are specific for the respective Gibbs energy of solvation and enthalpy of solvation into the given solvent. Given the documented success of eqs 2 and 3, it would not be unreasonable to assume that the basic model would be capable of describing the gas-to-liquid entropy of transfer, $\Delta S_{\text {Solv }}$,

$$
\Delta S_{\mathrm{Solv}}=c_{\mathrm{s}}+e_{\mathrm{s}} \cdot \mathbf{E}+s_{\mathrm{s}} \cdot \mathbf{S}+a_{\mathrm{s}} \cdot \mathbf{A}+b_{\mathrm{s}} \cdot \mathbf{B}+l_{\mathrm{s}} \cdot \mathbf{L}
$$

where the "s" subscript indicates the entropic component of the transfer process. Substituting the individual Abraham correlations for $\Delta H_{\text {Solv }}$ and $\Delta S_{\text {Solv }}$ into $\Delta G_{\text {Solv }}=\Delta H_{\text {Solv }}-T \Delta S_{\text {Solv }}$ yields

$$
\begin{aligned}
& \Delta G_{\text {solv }}=-2.303 R T \log K=c_{\mathrm{h}}+e_{\mathrm{h}} \cdot \mathbf{E}+s_{\mathrm{h}} \cdot \mathbf{S}+a_{\mathrm{h}} \cdot \mathbf{A}+ \\
& b_{\mathrm{h}} \cdot \mathbf{B}+l_{\mathrm{h}} \cdot \mathbf{L}-T\left(c_{\mathrm{s}}+e_{\mathrm{s}} \cdot \mathbf{E}+s_{\mathrm{s}} \cdot \mathbf{S}+a_{\mathrm{s}} \cdot \mathbf{A}+b_{\mathrm{s}} \cdot \mathbf{B}+l_{\mathrm{s}} \cdot \mathbf{L}\right)
\end{aligned}
$$

(5) Abraham, M. H.; Le, J.; Acree, W. E., Jr. Collect. Czech. Chem. Comm. 1999, 64, 1748-1760.

(6) Abraham, M. H.; Le, J.; Acree, W. E., Jr.; Carr, P. W. J. Phys. Org. Chem. 1999, 12, 675-680.

(7) Abraham, M. H.; Zissimos, A. M.; Acree, W. E., Jr. New J. Chem. 2003, 27, 1041-1044.

(8) Mintz, C.; Clark, M.; Acree, W. E., Jr.; Abraham, M. H. J. Chem. Inf. Model. 2007, 47, 115-121.

(9) Mintz, C.; Burton, K.; Acree, W. E., Jr.; Abraham, M. H. Thermochim. Acta 2007, 459, 17-25.

(10) Mintz, C.; Clark, M.; Burton, K.; W. E. Acree, W. E., Jr.; Abraham, M. H. QSAR Comb. Sci., published in electronic form as doi:10.1002/qsar.200630152.

(11) Mintz, C.; Clark, M.; Burton, K.; Acree, W. E., Jr.; Abraham, M. H. J. Solution Chem. 2007, 36, 947-966.

Analytical Chemistry, Vol. 79, No. 17, September 1, 20076891 
and

$$
\begin{array}{r}
\log K=\frac{c_{\mathrm{s}}}{2.303 R}-\frac{c_{\mathrm{h}}}{2.303 R T}+\left(\frac{e_{\mathrm{s}}}{2.303 R}-\frac{e_{\mathrm{h}}}{2.303 R T}\right) E+ \\
\left(\frac{s_{\mathrm{s}}}{2.303 R}-\frac{s_{\mathrm{h}}}{2.303 R T}\right) S+\left(\frac{a_{\mathrm{s}}}{2.303 R}-\frac{a_{\mathrm{h}}}{2.303 R T}\right) A+ \\
\left(\frac{b_{\mathrm{s}}}{2.303 R}-\frac{b_{\mathrm{h}}}{2.303 R T}\right) B+\left(\frac{l_{\mathrm{s}}}{2.303 R}-\frac{l_{\mathrm{h}}}{2.303 R T}\right) L
\end{array}
$$

a relatively simple mathematical expression. Over a small temperature interval, one would expect both the enthalpy and entropy of solvation to be independent of temperature. If this assumption holds, the 12 equation coefficients in eq 6 are temperatureindependent numerical values. Equation 6 suggests a method for combining $\log K$ values measured at different temperatures into a single correlation.

The Kamprad and Goss ${ }^{1}$ database of experimental adsorption coefficients for polyurethane ether LM2033 contains numerical values for up to 100 compounds at four temperatures between 15 and $95{ }^{\circ} \mathrm{C}$. For each solute, the authors measured the adsorption coefficient at one to four different temperatures. Several compounds were studied at only a single temperature. There is sufficient $\log K_{\text {PUF }}$ to develop a separate Abraham model correlation (eq 2):

$$
\begin{aligned}
& \text { at } T=288.15 \mathrm{~K} \\
& \begin{array}{r}
\log K_{\mathrm{PUF}}=0.045(0.095)-0.215(0.096) \mathbf{E}+ \\
1.643(0.086) \mathbf{S}+3.479(0.138) \mathbf{A}-0.134(0.101) \mathbf{B}+ \\
0.795(0.026) \mathbf{L}(7) \\
\left(N=45, \quad R^{2}=0.974, \quad R_{\text {adj }}^{2}=0.971, \quad \mathrm{SD}=0.087,\right. \\
F=297.6)
\end{array}
\end{aligned}
$$

at $T=308.15 \mathrm{~K}$

$$
\begin{gathered}
\log K_{\mathrm{PUF}}=-0.146(0.063)-0.165(0.070) \mathbf{E}+ \\
1.538(0.075) \mathbf{S}+2.800(0.124) \mathbf{A}+0.055(0.074) \mathbf{B}+ \\
0.735(0.016) \mathbf{L}(8) \\
\left(N=62, \quad R^{2}=0.983, \quad R_{\text {adj }}^{2}=0.982, \quad \mathrm{SD}=0.084,\right. \\
F=659.8)
\end{gathered}
$$

at $T=338.15 \mathrm{~K}$

$$
\begin{gathered}
\log K_{\mathrm{PUF}}=-0.323(0.036)-0.074(0.036) \mathbf{E}+ \\
1.327(0.045) \mathbf{S}+2.278(0.068) \mathbf{A}-0.005(0.049) \mathbf{B}+ \\
0.642(0.008) \mathbf{L}(9) \\
\left(N=67, \quad R^{2}=0.994, \quad R_{\text {adj }}^{2}=0.994, \quad \mathrm{SD}=0.052,\right. \\
F=204.9)
\end{gathered}
$$

at $T=368.15 \mathrm{~K}$

$$
\begin{array}{r}
\log K_{\mathrm{PUF}}=-0.250(0.047)-0.011(0.050) \mathbf{E}+ \\
1.092(0.065) \mathbf{S}+2.056(0.057) \mathbf{A}-0.026(0.070) \mathbf{B}+ \\
0.527(0.011) \mathbf{L}(10) \\
\left(N=91, \quad R^{2}=0.991, \quad R_{\text {adj }}^{2}=0.991, \quad \mathrm{SD}=0.089,\right. \\
F=1888.0)
\end{array}
$$

for each temperature. The $b$-equation coefficients are quite small

Table 1. Temperature-Independent Equation Coefficients for Eq 11 of the Abraham Model for Correlating the Gas-to-Polyurethane Ether Foam Adsorption Coefficients

coefficient

$$
\begin{aligned}
& c_{\mathrm{S}} \\
& c_{\mathrm{h}} \\
& e_{\mathrm{S}} \\
& e_{\mathrm{h}} \\
& s_{\mathrm{s}} \\
& s_{\mathrm{h}} \\
& a_{\mathrm{s}} \\
& a_{\mathrm{h}} \\
& b_{\mathrm{s}} \\
& b_{\mathrm{h}} \\
& l_{\mathrm{s}} \\
& l_{\mathrm{h}}
\end{aligned}
$$

numerical value (SD)

$$
\begin{aligned}
& -1.279(0.282) \\
& -354.607(94.673) \\
& 0.449(0.327) \\
& 179.41(109.48) \\
& -0.745(0.365) \\
& -692.187(119.576) \\
& -2.541(0.451) \\
& -1683.56(-154.97) \\
& -0.118(0.399) \\
& -33.83(130.48) \\
& -0.456(0.072) \\
& -365.896(24.46)
\end{aligned}
$$

and statistically insignificant and can be set equal to zero with no loss in descriptive ability. The molecular structure of a polyurethane ether suggests that the foam should exhibit very little (if any) acidic character. Here and elsewhere, $N$ corresponds to the number of solutes, $R$ denotes the correlation coefficient, SD is the standard deviation, and $F$ corresponds to the Fisher $F$-statistic. The $\log K_{\text {PUF }}$ values and solute descriptors used in the regression analyses are given in Table S1 (Supporting Information). The four temperature-specific correlations provide a benchmark to use in assessing how much predictive accuracy is lost whenever log $K_{\mathrm{LHA}}$ measured at different temperatures are combined into a single correlation.

The 265 experimental $\log K_{\mathrm{PUF}}$ values in Table S1 were analyzed collectively by regression analysis to yield the following correlation

$$
\begin{array}{r}
\log K_{\mathrm{PUF}}\left(L / g_{\mathrm{PUF}}\right)=c_{\mathrm{s}}-\frac{c_{\mathrm{h}}}{T}+\left(e_{\mathrm{s}}-\frac{e_{\mathrm{h}}}{T}\right) E+\left(s_{\mathrm{s}}-\frac{s_{\mathrm{h}}}{T}\right) S+ \\
\left(a_{\mathrm{s}}-\frac{a_{\mathrm{h}}}{T}\right) A+\left(b_{\mathrm{s}}-\frac{b_{\mathrm{h}}}{T}\right) B+\left(l_{\mathrm{s}}-\frac{l_{\mathrm{h}}}{T}\right) L
\end{array}
$$

(with $N=265, \quad R^{2}=0.988, \quad R_{\text {adj }}^{2}=0.987$,

$$
\mathrm{SD}=0.084, \quad F=1867.64)
$$

The calculated equation coefficients are listed in Table 1 . The calculated coefficients, when substituted into eq 11 for $T=308.15$ $\mathrm{K}$, gives

$$
\begin{array}{r}
\log K_{\text {PUF }}\left(L / g_{\text {PUF }}\right)=-0.128-0.133 \mathbf{E}+1.501 \mathbf{S}+ \\
2.922 \mathbf{A}-0.008 \mathbf{B}+0.731 \mathbf{L}
\end{array}
$$

which is in good agreement with the correlation obtained from regression analysis of the $308.15 \mathrm{~K}$ adsorption data. Equation 11 is statistically very good and describes an experimental data base that covers a $3.6 \mathrm{log}$ unit range to within a standard deviation of $0.084 \log$ unit (see Figure 1 for a graphical comparison of observed $\log K_{\mathrm{PUF}}$ data versus calculated values based on eq 11). Standard deviations for the four temperature-specific correlations (eqs 7-10 above) were also in the 0.05-0.09 log unit range.

Kamprad and Goss ${ }^{1}$ examined the influence of temperature on the sorption coefficients. The authors constructed a modified 


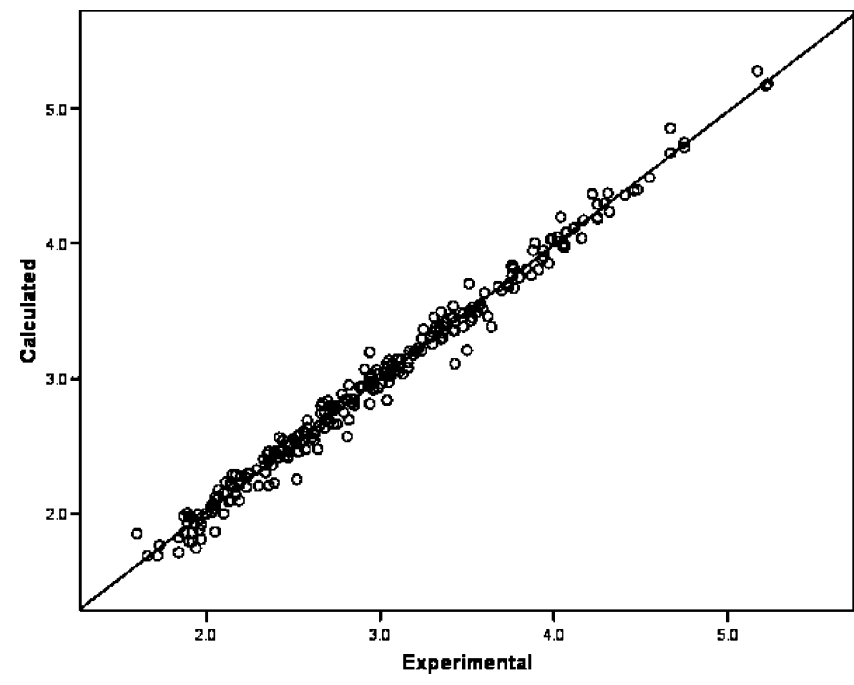

Figure 1. Comparison of experimental vs calculated absorption coefficients for polyurethane ether foam.

Abraham model correlation (see eq 1) for each temperature and then plotted the calculated numerical values of each equation coefficient versus the reciprocal of the absolute temperature. The plotted points do suggest a linear relationship, and one may infer from the way that the authors graphed the data that this was perhaps their intent. The authors though did not draw a straight line through the plotted points. The computational methodology we suggest by eq 11 assumes a linear relationship for each equation coefficient but does not require one to determine a mathematical correlation at each specific temperature. Our method combines partition coefficient data measured at different temperatures into a single correlation equation.

As part of our data analyses, we estimated how much predictive ability was likely to be lost as a result of using eq 11 and the coefficients in Table 1 to predict $\log K_{\text {PUF }}$ values rather than using the temperature-specific correlations that were developed for $288.15,308.15,338.15$, and $368.15 \mathrm{~K}$. To have a common basis for comparison, the difference between observed and calculated values based on eq 11 were expressed as

$$
\mathrm{SD}=\sqrt{\frac{\left(\log K_{\mathrm{calc}}-\log K_{\mathrm{obs}}\right)^{2}}{N-6}}
$$

for each of the four temperatures that we had a temperaturespecific Abraham model correlation. The results of our computations are summarized in Table 2. For the four temperatures considered, the standard deviations of eq 11 and the temperaturespecific correlations differ by an average of less than $0.02 \log$ unit. There is essentially no loss in predictive ability due to our proposed method of combining experimental data measured at different temperatures into a single correlation. We have elected to illustrate our proposed computational methodology with the
Table 2. Summarized Comparison of the Descriptive Ability of Eq 11 versus the Temperature-Specific Abraham Model Correlation Equations

\begin{tabular}{ccc} 
& \multicolumn{2}{c}{${\text { standard deviation }(\mathrm{SD})^{a}}^{a}$} \\
\cline { 2 - 3 } temperature $(\mathrm{K})$ & eq 11 & $\begin{array}{c}\text { temperature-specific } \\
\text { equations }\end{array}$ \\
288.15 & 0.128 & 0.087 \\
308.15 & 0.091 & 0.084 \\
338.15 & 0.066 & 0.052 \\
368.15 & 0.093 & 0.087 \\
$a \mathrm{SD}=\sqrt{\left(\left(\log K_{\text {calc }}-\log K_{\mathrm{obs}}\right)^{2}\right) /(N-6)}$ & \\
\hline
\end{tabular}

original Abraham model because this form of the model has been shown to describe enthalpies of solvation of gaseous solutes in both water and several organic solvents. The methodology can be used also with the modified Abraham model employed by Kamprad and Goss; ${ }^{1}$ however, there have been far fewer published studies that used the modified model.

The advantage that eq 11 has over the temperature-specific Abraham model correlation is that one is able to utilize more of the available experimental data. For example, lets assume that one was able to find $\log K_{\mathrm{PUF}}$ data for 20 compounds at $288.15 \mathrm{~K}$, $\log K_{\text {PUF }}$ data for a different set of 20 compounds at $308.15 \mathrm{~K}$ and $\log K_{\text {PUF }}$ data for a third set of 20 compounds at $368.15 \mathrm{~K}$. There would be insufficient experimental data to develop an Abraham model correlation. Generally one needs a minimum of $30-40$ data points (preferably more) to develop a meaningful correlation equation, and the compounds need to span as wide of a range of solute descriptors as possible. By combining the $60 \log K_{\mathrm{PUF}}$ values into a single database, one could develop a predictive expression based on eq 11. Such predictions would otherwise not be possible with our existing regression model that requires all experimental data be at the same temperature. We will continue to develop temperature-specific correlations and enthalpy of solvation correlations whenever there is sufficient experimental data to do so. In instances of limited experimental data at a common temperature, eq 11 can be used to develop a strictly predictive expression by combining experimental data measured at different temperatures.

\section{SUPPORTING INFORMATION AVAILABLE}

Logarithms of the experimental gas-to-polyureathane ether adsorption coefficients, $\log K_{\text {PUF }}$ data, and numerical values of the Abraham solute descriptors used in the regression analyses. This material is available free of charge via the Internet at http:// pubs.acs.org.

Received for review June 30, 2007. Accepted July 12, 2007.

AC071384F 